\title{
Management of kidney cancer: Canadian Kidney Cancer Forum Consensus Update
}

\author{
Canadian Kidney Cancer Forum 2009
}

Can Urol Assoc J 2009;3(3):200-4

K idney cancer, predominantly renal cell carcinoma (RCC), remains the most lethal genitourinary malignancy and kills more than 1500 Canadians a year. ${ }^{1}$ In 2008, the first Canadian Kidney Cancer Forum was held and a clinical management consensus was developed and reported. ${ }^{2}$ In January 2009, a second forum was convened near Toronto, Ont., with multidisciplinary attendees, this time including researchers and the Board of Kidney Cancer Canada (www.kidneycancercanada.org).

During the conference, the 2008 consensus was reviewed and updated using the same process. This report is a brief overview of those updates using the same format and should be read in conjunction with that report. ${ }^{2}$ Explanatory text has been omitted in this version if no significant new information has become available. This document represents the current consensus of the attendees who are now the founding members of a new organization, the Kidney Cancer Research Network of Canada. This network will be the subject of future discussion and reports but is intended to begin as an informal, inclusive virtual network of researchers; clinical, translational and basic, with a common interest in kidney cancer research. The forum addressed strategies for kidney cancer control in Canada, which included planning for a Canadian Kidney Cancer Database, collaboration to validate follow-up guidelines defined by the Canadian Urological Association, a coordinated approach to genetic testing for genes relevant to kidney cancer and the initiation of a process to define quality indicators for the management of kidney cancer as part of an overall strategy to define centres of excellence. ${ }^{3}$ The attendees are developing a position paper on kidney cancer education, research and treatment in Canada that will include the full consensus combining this update with the 2008 statements.

Finally, the forum was held with Kidney Cancer Canada whose members continue to monitor access to targeted therapeutic agents across the country. Attendees reaffirmed their support for equal access to these treatments for all Canadians in whom there is a clinical rationale.

\section{Management of localized kidney cancer}

Role of renal biopsy

- Needle biopsy for histological diagnosis may be considered before treatment of small $(<3 \mathrm{~cm})$ enhancing solid tumours and at the time of probe ablation

There continues to be growing experience with percutaneous needle core biopsy of early stage renal tumours indicating that it is relatively safe and diagnostic in most cases. ${ }^{4,5}$ The high rate of benign pathology in tumours managed by surgery or ablation is leading to a paradigm shift to consider biopsy in all small tumours before treatment, and the previous statement, "in patients with significant comorbities or limited life expectancy" has been deleted for this reason. However, this has not yet become a standard of care and requires local expertise with image-guided biopsy techniques and pathological interpretation.

\section{Treatment options}

\section{Stage TlaNOMO}

\section{- Open partial nephrectomy recommended}

- Pure and/or robot-assisted laparoscopic partial nephrectomy in experienced centres

- Laparoscopic radical nephrectomy for tumours not amenable to partial nephrectomy

- Probe ablation by radiofrequency or cryotherapy. A biopsy should be obtained before or at the time of ablation

\section{- Active surveillance}

There is increasing concern about nephrectomy as opposed to nephron-sparing surgery for kidney cancer. It is becoming clearer that partial nephrectomy is associated with a lower risk of long-term renal dysfunction. ${ }^{6,7}$ There is no evidence that oncological outcomes are adversely affected by partial nephrectomy and there may be overall quality-of-life benefits..$^{8-10}$ 
Laparoscopic partial nephrectomy is increasingly available in Canada and experience with robot-assisted laparoscopic partial nephrectomy has been reported from several centres. ${ }^{11,12}$ Probe ablation is becoming more widely accepted and practised, but it is important to have a biopsy before or at the time of treatment for follow-up planning and outcome analysis. ${ }^{13}$

\section{Stage TIbNOMO}

- Partial nephrectomy in cases where technically feasible

- Laparoscopic radical nephrectomy should be offered if a partial nephrectomy is not feasible

The consensus has changed from 2008 and partial nephrectomy is now recommended. Partial nephrectomy is rapidly emerging as the treatment of choice when technically feasible (e.g., select cases such as exophytic tumours) and should be offered. There are several series demonstrating the feasibility, safety and efficacy of partial nephrectomy for tumours $4-7 \mathrm{~cm} .{ }^{14,15}$ There is now further evidence to support the benefits of partial nephrectomy and there may be an overall survival benefit to partial nephrectomy. ${ }^{7}$ Surgical expertise with this procedure is increasingly available but it is an advanced renal procedure. If a partial nephrectomy is not feasible, laparoscopic radical nephrectomy is the surgery of choice in this setting and is preferred to open radical nephrectomy. Open surgery is recommended for $\mathrm{N}+$ disease. Probe ablation is not recommended for these tumours owing to the high rate of incomplete ablation. ${ }^{16,17}$

There was no change in the consensus of 2008 for T2 and higher stage tumours. Similarly, the role for surveillance in localized disease consensus is unchanged.

\section{Surveillance schedules after radical or partial nephrectomy}

The draft guidelines recommended by the Canadian Urological Association were reproduced in the previous consensus but the imaging modality has been modified to include ultrasonography as an option for T1-T2 tumours in the final guidelines and is reproduced in Figure 1 (www.cua.org/guidelines). ${ }^{3}$

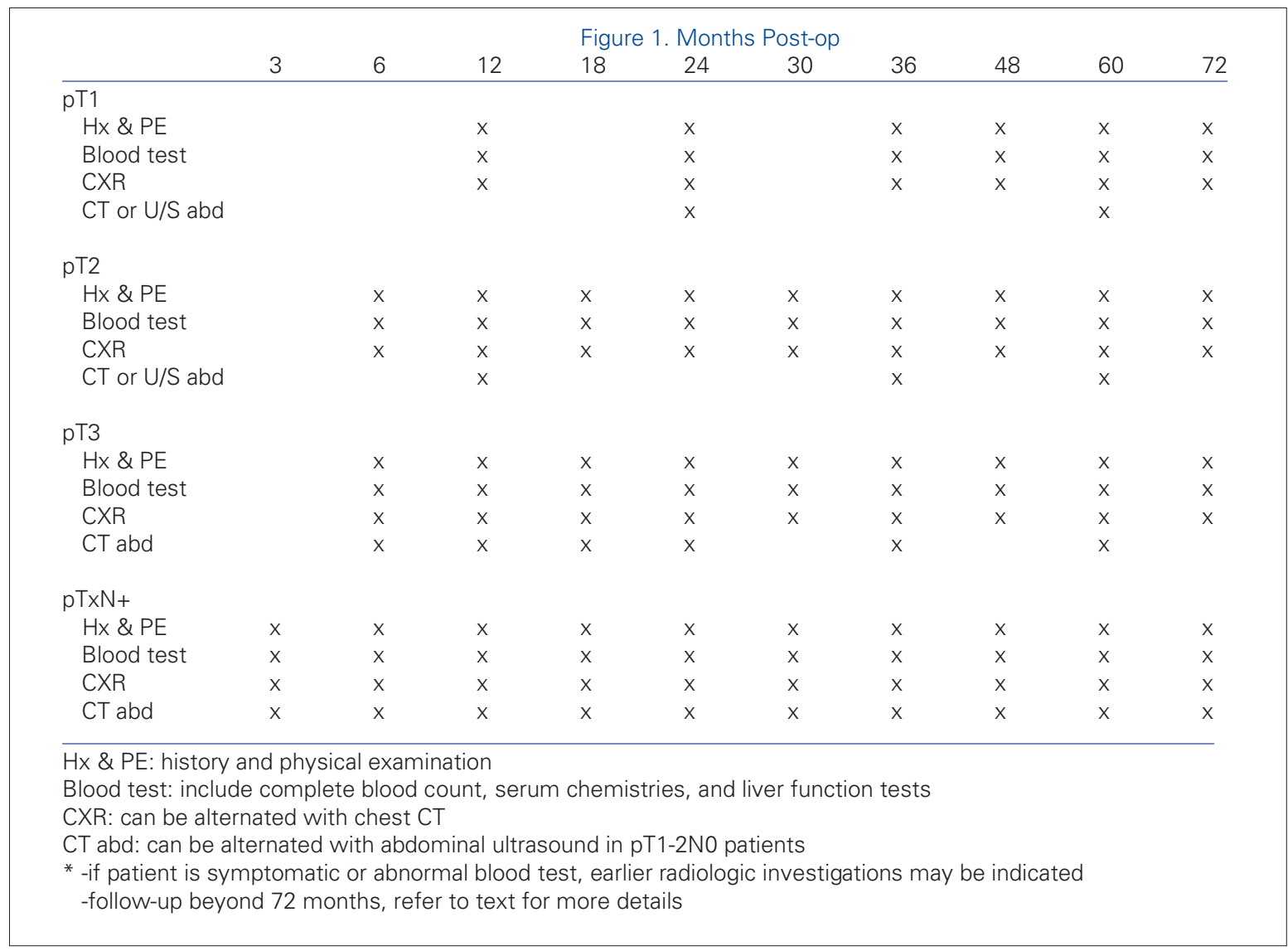

Fig. 1. Contemporary surveillance protocols based on stage-based stratifications. 


\section{Management of locally advanced kidney cancer}

Adjuvant and neoadjuvant systemic therapy remains experimental and is not indicated in clinical practice at this time.

\section{Role of lymphadenectomy}

- Lymphadenectomy is optional for clinical N0M0 disease

- In $\mathrm{N}+\mathrm{MO} /+$ patients undergoing nephrectomy, lymphadenectomy including all abnormal nodes should be performed and submitted separately for staging

Although there were no changes in the consensus, there was discussion about the role for lymphadenectomy in N0 patients. ${ }^{18,19}$ It was felt that if the primary tumour is locally advanced, or enlarged nodes are discovered at surgery, they should be removed including nodes in an ipsilateral template. There is no clear evidence for the limits of dissection but the lymphatics from right-sided tumours drain to the interaortic nodes, while those on the left may only drain initially to nodes anterior, posterior and lateral to the aorta. The optimal minimum number of nodes is unknown but may be in the order of $13 .{ }^{20}$ High-risk features in the primary tumour appear to correlate with the presence of nodal metastases, even if nodes are grossly normal. (Leibovich, BC, Mayo Clinic, Rochester, Minn.: personal communication, 2009). This may be an additional indication for lymphadenectomy. N0 disease in the face of metastases elsewhere may be an indication for lymphadenectomy. The morbidity and additional operative time are minimal but the oncological benefit is unknown. In the event that adjuvant therapy is found to be beneficial, the role for lymphadenectomy may change.

\section{Advanced (metastatic) kidney cancer}

Again, enrolling patients in well-designed clinical trials should always be considered as the first option for patients with advanced or metastatic RCC.

\section{First-line therapy}

- Sunitinib is the preferred first-line treatment

- Temsirolimus is a treatment option for patients with adverse risk factors

- Observation can also be considered, as for some patients who have slow-growing asymptomatic disease

- High-dose interleukin-2 (IL-2) can be considered for selected patients

Based on phase III data, sunitinib produces higher response rates, improved quality of life, and a longer progression-free survival and, now, overall better survival than interferon does in patients with clear cell carcinoma. ${ }^{21,22}$ In a subsequent analysis that censored patients who crossed over to sunitinib from interferon, overall survival was seen. ${ }^{23}$ In addition, population-based studies from British Columbia and Alberta have shown an almost doubling of overall survival of metastatic renal cell carcinoma (mRCC) since the introduction of sunitinib, and sunitinib or sorafenib, respectively. ${ }^{24,25}$ Based on phase III data, temsirolimus produces an improvement in progression-free and overall survival in poorer risk patients than interferon alone or the combination of temsirolimus and interferon. Poorer risk was defined by at least 3 out of 6 of the following criteria: Karnofsky Performance Scale score greater than 60-70, $\uparrow \mathrm{Ca}^{2+}, \downarrow \mathrm{Hgb}, \uparrow \mathrm{LDH}$, less than 1 year from nephrectomy to treatment, multiple metastatic sites. ${ }^{26}$ Where drug access is limited, everolimus, if available, would be a reasonable alternative. In patients with intolerance to sunitinib or temsirolimus, sorafenib remains a good option. ${ }^{27}$ There is phase III data demonstrating the combination of bevacizumab plus interferon improves progression-free survival over interferon alone, although the trial is too early for survival data. ${ }^{28}$ At this time, there has been no application submitted regarding bevacizumab for the kidney cancer indication in Canada, and so it is not a likely option for Canadian patients.

In patients with metastatic or advanced RCC with non-clear cell pathology, consideration for clinical trials of new agents should be considered. Other options include sunitinib, based on subgroup analyses from the expanded access trial showing safety and activity; sorafenib, based on subgroup analyses from the Advanced Renal Cell Carcinoma Sorafenib (ARCCS) expanded access trial showing safety and activity; and temsirolimus, based on subgroup analysis of phase III data. ${ }^{29-31}$

In the opinion of attendees, observation is a reasonable option, especially given that no therapies are currently considered curative, and that all available treatments can be associated with side effects.

When prescribing systemic therapy for advanced or metastatic RCC, several key factors must be taken into account. An oncology specialist knowledgeable about the acute and long-term toxicities, drug interactions, and monitoring treatment and response, should prescribe therapy. Patients should be managed in a multidisciplinary environment with adequate nursing care, dietary care, pharmacy support, and so on. Patients must be evaluated frequently to ensure toxicities are recognized and managed appropriately. Patients should be provided with information concerning potential side effects, prevention and treatment.

No phase III studies of the use of IL-2 have shown an 
improvement in survival, and thus it is not considered to be a standard of care. High-dose IL-2 must be delivered in specialized and experienced IL-2 treatment centres and ideally in the context of a clinical trial or investigational setting. Low-dose IL-2 should not be given. ${ }^{32,33}$

\section{Progression on or intolerance to cytokines}

Recommendations for this section are based on level I evidence. Based on phase III data, sorafenib improved progression-free survival compared with best supportive care alone in previously treated patients. Overall survival data was confounded by crossover but reached significance when censored for crossover. ${ }^{27}$ Sunitinib is an alternate treatment. Based on 2 phase II trials, sunitinib produced significant response rates and increased progression-free survival compared with historical controls. ${ }^{21}$

\section{Progression after first-line therapy}

\section{- Switch to another targeted agent, ideally everolimus} when available

- Clinical trials in this population should be supported as the optimal sequence if therapies are unknown

Based on phase III data, everolimus (oral mammalian target of rapamycin inhibitor) produced a significantly longer progression-free survival than placebo, with acceptable toxicity profile in patients who had failed sunitinib or sorafenib (often both). ${ }^{28}$ This represents the best data to date for sequence therapy. Everolimus is under review by Health Canada. Temsirolimus is a reasonable alternative given its similar mode of activity. In patients with advanced or metastatic RCC after sunitinib or sorafenib failure, other options include switching to another tyrosine kinase inhibitor (TKI) (e.g., from sunitinib to sorafenib or from sorafenib to sunitinib), based on emerging data showing activity with sequential therapy; and interferon, based on limited data but activity in previous phase II studies. ${ }^{34-36}$

In patients with advanced or metastatic sarcomatoid or poorly differentiated RCC, options include sunitinib, based on prospective, nonrandomized data from the Expanded Access Program; sorafenib, based on prospective, nonrandomized data from the ARCCS expanded access trial; chemotherapy, based on phase II data using agents such as 5 -fluorouracil, gemcitabine, doxorubicin and combinations of these showing activity; and temsirolimus, based on subgroup analysis from the pivotal phase III trial in which these patients were eligible..$^{29-31,37,38}$

- Cytoreductive nephrectomy is recommended to improve

\section{overall survival in appropriately selected patients with mRCC planned to receive interferon- $\alpha 2 b$ immunotherapy}

Recommendations for this section are based on level I evidence. Appropriately selected patients for cytoreductive nephrectomy include patients with a primary tumour of clear cell histology amenable to surgical extirpation and a low risk of perioperative morbidity, patients with good performance status (ECOG 0 or 1 ) and patients without evidence of brain metastases. . $^{32,39,40}$

Recognizing that most patients will be planned for TKI therapy rather than cytokine therapy, further study on the true benefit of cytoreductive nephrectomy is required. Although this question may be addressed in planned clinical trials, there are no data to guide clinical practices at this time. Decisions are to be made based on clinical indications. Nephrectomy likely will not be harmful based on the fact that about $90 \%$ of enrolled patients received nephrectomy before systemic therapy in both the sunitinib and the sorafenib phase III trials. ${ }^{21,27}$ In patients with response to TKI or targeted therapy, limited metastatic disease and good performance status, it is reasonable that cytoreductive nephrectomy be considered.

It has been recommended that the forum reconvene in 2011 to re-evaluate the consensus arrived at in 2008 and 2009.

The Canadian Kidney Cancer Forum 2009 took place in Toronto, Ont., Jan. 22-24, 2009. Members of the Steering Committee included M.A.S. Jewett, A. Finelli, C. Kollmannsberger, L. Wood, L. Legere. The Program Committee included A. Finelli, G. Bjarnason, A. Kapoor, P. Karakiewicz, L. Lacombe, M. MacKenzie, R. Rendon, S. Tanguay, P. Venner, R. Wong. Other presenters included M. Care, J. Chin, T. Clark, R. Clarke, J. Ebos, M. Guba, T. Hudson, J. Kachura, S. KamelReid, W. Kassouf, J. Knox, B. Leibovich, M. Linehan, D. Maskens, P. O'Brien, S. Pautler, N. Reaume, B. Rini, T. Sills, S. Quaggin, E. Winquist. Participants included A. Abugaber, H. Assi, A. Atwell, N. Bajula, J. Basiuk, P. Black, N. Blais, M. Brigden, I. Cagiannos, C. Canil, F. Carbonneau, T. Chen, D. Drachenberg, N. Drayton, K. Durrant, A. Evans, B. Fairfield, R. Grant, D. Heng, J. Kawakami, L. Klotz, G. Kurban, K. Kyryluk, I. Link, I. McAuley, J. McCarthy, G. Menard, J. Michels, R. Moore, C. Morash, S. North, N. Pace, A. Pause, E. Pituskin, T. Pizioli, I. Reid, D. Ruether, A. Shoker, K. Sridhar, L. Taylor L, T. Truong.

This article has been peer reviewed.

Competing interests: None declared.

\section{References}

1. Canadian Cancer Society, National Cancer Institute of Canada. Canadian cancer statistics, 2008. Toronto: The Institute; 2008.

2. Canadian Kidney Cancer Forum. Management of kidney cancer: Canadian Kidney Cancer Forum Consensus Statement. Can Urol Assoc J 2008;2:175-82.

3. Kassouf W, Siemens R, Morash C, et al. Follow-up guidelines after radical or partial nephrectomy for localized and locally advanced renal cell carcinoma. Can Urol Assoc J 2008;3:73-6.

4. Volpe A, Kachura JR, Geddie WR, et al. Techniques, safety and accuracy of sampling of renal tumors by fine needle aspiration and core biopsy. J Urol 2007;178:379-86.

5. Lane BR, Samplaski MK, Hertws BR, et al. Renal mass biopsy: a renaissance? J Urol 2008;179:20-7. 
6. Huang WC, Levey AS, Serio AM, et al. Chronic kidney disease after nephrectomy in patients with renal cortical tumours: a retrospective cohort study. Lancet Oncol 2006;7:735-40..

7. Thompson RH, Boorijan SA, Lohse CM, et al. Radical nephrectomy for pTla renal masses may be associated with decreased overall survival compared with partial nephrectomy. J Urol 2008;179:472-3.

8. Fergany AF, Hafez KS, Novick AC. Long trem results of nephron sparing surgery for localized renal cell carcinoma: 10-year followup. J Urol 2000;163:442-5.

9. Becker F, Siemer S, Humke U, et al. Elective nephron sparing surgery should become standard treatment for small unilateral renal cell carcinoma: Long-term survival data of 216 patients. Eur Urol 2006; 49:308-13.

10. Lesage K, Joniau S, Francis K, et al. Comparison between open partial and radical nephrectomy for renal tumours: perioperative outcome and health-related quality of life. Eur Urol 2007;51:614.

11. Wang AJ, Bhayani SB. Robotic partial nephrectomy versus laparoscopic partial nephrectomy for renal cell carcinoma: single-surgeon analysis of $>100$ consecutive procedures. Urology 2009;73:306-10.

12. Ho H, Schwentner C, Neururer R, et al. Robotic-assisted laparoscopic partial nephrectomy: surgical technique and clinical outcomes at 1 year. BJU Int 2009;103:663-8

13. Kunkle DA, Uzzo RG. Cryoablation or radiofrequency ablation of the small renal mass: a metaanalysis. Cancer 2008; 15:2671-80.

14. Leibovich BC, Blute ML, Cheville JC, et al. Nephron sparing surgery for appropriately selected renal cell carcinoma between 4 and $7 \mathrm{~cm}$ results in outcome similar to radical nephrectomy. J Urol 2004;171: $1066-70$.

15. Peycelon $M$, Hupertan $V$, Comperat $E$, et al. Long-term outcomes after nephron sparing surgery for renal cell carcinoma larger than $4 \mathrm{~cm}$. J Urol 2009;181:35-41.

16. Gervais, DS, Arellano RS, McGovern FJ, et al. Radiofrequency ablation of renal cell carcinoma: part 2, lessons learned with ablation of 100 tumors. AJR Am J Roentgenol 2005; 85:72-80.

17. Zagoria RJ, Traver MA, Werle DM, et al. Oncologic efficacy of CT-guided percutaneous radiofrequency ablation of renal cell carcinomas. AJR Am J Roentgenol 2007;189:429-36.

18. Pantuck AJ, Zisman A, Dorey F, et al. Renal cell carcinoma with retroperitoneal lymph nodes: impact on survival and benefits of immunotherapy. Cancer 2003;97:2995-3002.

19. Leibovich $B C$, Blute ML. Lymph node dissection in the management of renal cell carcinoma. Urol Clin North Am 2008:208:673-8.

20. Terrone C, Guercio $S$, De Luca $S$, et al. The number of lymph nodes examined and staging accuracy in renal cell carcinoma. BJU InI 2003;91:37-40.

21. Motzer RJ, Basch E. Targeted drugs for metastatic renal cell carcinoma. Lancet 2007;370:2071-3.

22. Bukowski RM, Eisen T, Szczylik C, et al. Final results of the randomized phase III trial of sorafenib in advanced renal cell carcinoma: survival and biomarker analysis. J Clin Oncol 2007;25(18S):5023.

23. Figlin R, Hutson TE, Tomczak $P$, et al., Overall survival with sunitinib versus interferon (IFN)-alfa as first-line treatment of metastatic RCC(mRCC). J Clin Oncol 2008;26:5024.

24. Heng DYC, Chi KN, Murray N, et al. A population-based study evaluating the impact of sunitinib on overall survival in the treatment of patients with mRCC. Cancer 2009;115;776-83.
25. Warren, MA, Venner PM, North SA, et al. Then and now: The effect of tryrosine kinase inhibitors on survival in patients with metastatic renal cell carcinoma in Alberta, Canada. J Clin Oncol 2008;26:16033.

26. Hudes $G$, Carducci $M$, Tomczak $P$, et al. Temsirolimus, interferon alfa, or both for advanced renal-cell carcinoma. N Engl J Med 2007;356:2271-81

27. Escudier B, Eisen T, Stadler WM, et al. Sorafenib in advanced clear-cell renal-cell carcinoma. N Engl J Med 2007;356:125-34

28. Motzer RJ, Escudier B, Oudard S. Efficacy of evirolimus in advanced renal cell carcinoma:a double blind, randomized, placebo-controlled phase III trial. Lancet 2008;372:449-56.

29. Gore ME, Porta C, Oudard $\mathrm{S}$, et al. Sunitinib in metastatic renal cell carcinoma (mRCC): preliminary assessment of toxicity in an expanded access trial with subpopulation analysis. I Clin Oncol 2007;25 (18S):5010.

30. Dutcher JP, Szczylik C, Tannir N, et al. Correlation of survival with tumor histology, age, and prognostic risk group for previously untreated patients with advanced renal cell carcinoma (adv RCC) receiving temsirolimus (TEMSR) or interferon-alpha (IFN). J Clin Oncol 2007;25(18S):5033.

31. Knox JJ, Figlin RA, Stadler WM, et al. The Advanced Renal Cell Carcinoma Sorafenib (ARCCS) expanded access trial in North America: safety and efficacy. J Clin Oncol 2007;25(18S):5011.

32. Cancer Care. Ontario Genitourinary Cancer Practice Guidelines. 2006. Available: www. cancercare.on.ca/ toolbox/qualityguidelines/diseasesite/genito-ebs/ (accessed 2009 May 12)

33. Negrier S, Perol D, Ravaud A, et al. Medroxyprogesterone, interferon alfa-2a, interleukin 2, or combination of both cytokines in patients with metastatic renal carcinoma of intermediate prognosis: results of a randomized controlled trial. Cancer 2007;110:2468-77.

34. Sablin MP, Bouaita L, Balleyguier C, et al. Sequential use of sorafenib and sunitinib in renal cancer: retrospective analysis in 90 patients. J Clin Oncol 2007;25(185):5038.

35. Tamaskar I, Garcia JA, Elson P, et al. Antitumor effects of sunitinib or sorafenib in patients with metastatic renal cell carcinoma who received prior antiangiogenic therapy. J Urol 2008;179:81-6.

36. Hott S. Guidelines for mRCC. In press.

37. Stadler WM, Figlin RA, Ennstof MS, et al. The Advanced Renal Cell Carcinoma Sorafenib (ARCCS) expanded access trial: safety and efficacy in patients (pts) with non-clear cell (NCC) renal cell carcinoma (RCC). J Clin Oncol 2007;25(185):5036.

38. Nanus DM, Garino A, Milowsky MI, et al. Active chemotherapy for sarcomatoid and rapidly progressing renal cell carcinoma. Cancer 2004;101:1545-51.

39. Flanigan RC, Mickisch G, Sylvester R, et al. Cytoreductive nephrectomy in patients with metastatic renal cancer: a combined analysis. J Urol 2004;171:1071-6.

40. Mickisch GH. Urologic approaches to metastatic renal cell carcinoma. Onkologie 2001;24:122-6.

Correspondence: Dr. Michael Jewett, Division of Urology, University of Toronto, 610 University Ave., 3-124, Toronto ON M5G 2C4; fax 416 598-9997; m.jewett@utoronto.ca 